\title{
Level of Reflective Practice amongst Saudi Female Postgraduate Students at KSU
}

\author{
Sozan H. Omar ${ }^{1}$, Fatimah A. Al-Kathiri ${ }^{2} \&$ Sarah A. Al-Ajmi ${ }^{2}$ \\ ${ }^{1}$ Assistant Professor in Curriculum \& Instruction, Science Education, KSU, Riyadh, Saudi Arabia \\ ${ }^{2} \mathrm{PhD}$ Students, Curriculum \& Instruction Department, KSU, Riyadh, Saudi Arabia \\ Correspondence: Fatimah A. Al-Kathiri, Curriculum \& Instruction Department, KSU, Riyadh, Saudi Arabia. \\ E-mail: fatimakathiri@gmail.com
}

\author{
Received: May 30, 2017 Accepted: June 22, 2017 Online Published: August 9, 2017 \\ doi:10.5539/ells.v7n3p28 URL: http://doi.org/10.5539/ells.v7n3p28
}

\begin{abstract}
This paper investigates the level of reflective practice amongst Saudi female postgraduate students at King Saud University. The study is quantitative in nature, whereby a reflective practice self-assessment scale was administered to assess the reflective practice of 201 female postgraduate students at KSU. The scale concentrates on five dimensions; the ability and freedom to reflect, questioning assumptions, considering others' viewpoints, using reflective methods/tools, and frequency of the refection on events. Findings of this study indicate that Saudi female postgraduate students at KSU reveal a decent level of reflective skills. Findings also display that there are some reflective requirements and skills which are more common in the scientific fields than they are in the literary fields. On the light of these results, recommendations for Saudi postgraduate instructors and program developers are provided accordingly.
\end{abstract}

Keywords: reflective practice, postgraduate students

\section{Introduction}

\subsection{Background}

Reflective practice is a deliberate way of thinking about experiences: to learn from mistakes, to identify skills and strengths and to develop options and actions for change and future success (Al-Ahdal, 2014). In fact, reflective Practice is more than recording training for continuing professional development. Instead, it links reflection and action together, to encourage critical thinking for new knowledge and insights, enabling lifelong learning and development .

In addition, the rapid development of education in the twenty-first century requires learners to become more independent and reflective learners. They are expected to acquire the capacity to engage in reflective practices, as having such skills will help them to develop higher-order thinking skills by relating new knowledge to prior understanding, thinking in both abstract and conceptual terms, applying specific strategies in novel tasks, understanding their own thinking and learning strategies and becoming effective in their professional contexts (Khalid, Ahmad, Karim, Daud, \& Din, 2015).

Within postgraduate education, there is an increasing emphasis on the need for reflection as an integral part of learning to learn. Students are not only expected to reflect as a part of their subject-based studies, but also to reflect on their learning and development of skills. When students join postgraduate programs, we expect them to act as reflective practitioners and to exercise professional judgment. In fact, there has been a concerted effort among universities and institutions of higher education to incorporate reflective thinking into their curriculum (YuekMinga \& Abd Manaf, 2014).

In Saudi Arabia, there has been an increasing interest in the role of reflection in higher education, especially amongst postgraduate students (Sibahi, 2015). And although recent research is united in proclaiming the benefits of reflective practice for the development of research skills, it is important to note that many constraints such as issues of time, personal motivation and the lack of training may have a significant impact on reflective practice development (Almazrawi, 2014). Amidst all these constraints, do postgraduate students still practice reflective thinking and, if so, how much do they reflect? And what forms of reflection do they use in their practice? 


\subsection{Statement of the Problem}

Despite the acclaimed virtues of reflective practice, it is important to note that practicing deep reflection takes time and dedication, and that teaching in higher education sector entails many responsibilities that might prevent students from developing such important skills. In the Saudi context, unfortunately, there is a slow adoption of reflective practice in higher education programs (Almorshid, 2014). Although reflection as a learning concept is well-researched by scholars, its practical application, especially in terms of postgraduate students' education programs, needs to be studied thoroughly (Fielden, 2008). Consequently, this study may contribute to the academic exploration of reflective practice in the context of higher education programs. It will also provide a closer look into the postgraduates' way of thinking about their daily events, clarifying to what extent they go in their reflection and what methods they use. Besides that, it will identify which skills already exist among the Saudi female postgraduate students through surveying a number of them, bringing the voice of students into life to present a realistic view of the current situation and inspiring more practical plans for the future.

\subsection{Research Questions}

The current study seeks answers to the following questions:

1) What is the level of reflective practice amongst Saudi female postgraduate students at King Saud University?

2) Are there any significant differences in the level of reflective practice between the literary and scientific fields?

\subsection{Significance of the Study}

The findings of this study can be significant for many reasons:

a. They can provide important information about the ways Saudi female postgraduates practice reflective thinking, so as to construct a meaningful profile of their ability to think through the routine actions of life and to investigate the features of how a reflective practitioner should act.

b. The data collected in this study could be of great value to policy makers and postgraduate programs coordinators to better ensure productive use of reflective thinking in education. Responses from students who practice such thinking, followed by careful analysis, could be an important step in the assessment and modification of the teaching and learning initiative.

c. The study might also assist postgraduate curriculum designers in deciding whether skills and knowledge related to reflective thinking should be introduced within their curriculum. It might also encourage faculty members to develop new objectives and appropriate strategies tools that make reflective teaching and learning in Saudi higher education more effective and interesting.

d. The results of the study might offer relevant information to redesign training programs that would better prepare faculty members in Saudi universities to meet their responsibilities towards students by equipping them with appropriate knowledge and skills of reflective practice to enrich both their research ability and their continued professional development.

\section{Review of Literature}

To build a shared understanding of what the term reflective practice means, it is necessary to explore the concept in more details. This section provides a holistic view of what reflective practice really is, distinguishes between its different models and frameworks, provides an overview of its dimensions in postgraduate education and discusses the notion of postgraduate student as a reflective practitioner.

\subsection{The Concept of Reflective Practice}

Reflective practice has flourished over the last few decades throughout various fields of professional practice and education. In some professions, it has become one of the defining features of competence. In fact, reflective practice is not a new concept. The origins of reflective practice can be traced back to the educational philosopher John Dewey (1933), who defined reflection as "an active, persistent, and careful consideration of any belief or supposed form of knowledge in light of the grounds that support it and the future conclusions to which it tends" (cited in Sibahi, 2015, p. 339).

Reflective practice is a forum of response of the learner to experience, featuring the individual and his or her experiences and leading to a new conceptual perspective or understanding (McClure, 2008). Finlay (2008) argues that the term 'reflective practice' carries multiple meanings that range from the idea of professionals engaging in solitary introspection to that of engaging in critical dialogue with others, and adds that practitioners 
may embrace it occasionally in formal, explicit ways or use it more fluidly in ongoing, tacit ways.

Most educational discourse surrounding reflective practice emphasizes personal experience as a significant constituent in the learning process and that learning should be to some extent self-directed (Smith, 2016). Bolton (2014) observes that the term reflective practice has mirror-like connotations, producing a superficial reflection of the self. In addition, Swanwick, Kitchen, Jarvis, McCracken, O'Neil \& Powers (2014) advocate an approach called though-the-mirror; in which we venture through the mirror to experience things from alternative scenarios and viewpoints. This approach highlights the requirement of internal inquiry, putting oneself in another's shoes, and exploring the world from different perspectives. Reflective practice is also defined as the integration of intentional through and specific actions within a professional contexture and is outlined as the process generating praxis, which can be also positioned as conversant, devoted, and dedicated action (Tarrant, 2013). Finlay (2008) maintains that, when facing problems, professionals need to draw on both practical experience and theory as they improvise, invent, refine and act. We can engage in reflection in one of two ways: either by "reflection in action", which takes place while we are involved in the situation and draws upon theories in use, or "reflection on action", which takes place after the situation has happened and draws upon teaching experience and espoused theories (Rolfe, 2011).

However, Buwert (2012) claims that the two previous ways failed to recognize the importance of "reflection before action", which encourages people to connect with past experiences before engaging in the present activities. Sibahi (2015), on the other hand, advocates "reflection for action", which links reflective thinking to future action and suggests analyzing one's behavior with the designated purpose of taking some action to change. Ekebergh (2007) further argues that it is impossible to distance oneself from the lived situation to reflect in the moment, and to achieve real self-reflection one needs to step out of the situation and reflect retrospectively.

\subsection{Models of Reflective Practice}

A number of models of reflection have been advanced in different fields of professional practice and education. Finlay (2008) believes that these models vary in their levels of prescription, explanation, criticality and reflexivity, but most share a focus on reflection as being essentially retrospective. Finlay (2008) also argues that they all tend to involve three fundamental processes:

- Retrospection: i.e., thinking back about a situation or experience.

- Self-evaluation: i.e., critically analyzing and evaluating the actions and feelings associated with the experience, using theoretical perspectives.

- Reorientation: i.e., using the results of self-evaluation to influence future approaches to similar situations or experiences.

McClure (2008) adds that according to Kolb (1984), reflecting is an essential element of learning in which effective learning will not occur unless reflection occur that implies thinking of a particular moment in time and ponder over it. This approach to learning can be illustrated through an experiential learning cycle (Figure 1).

Kolb's Learning Cycle

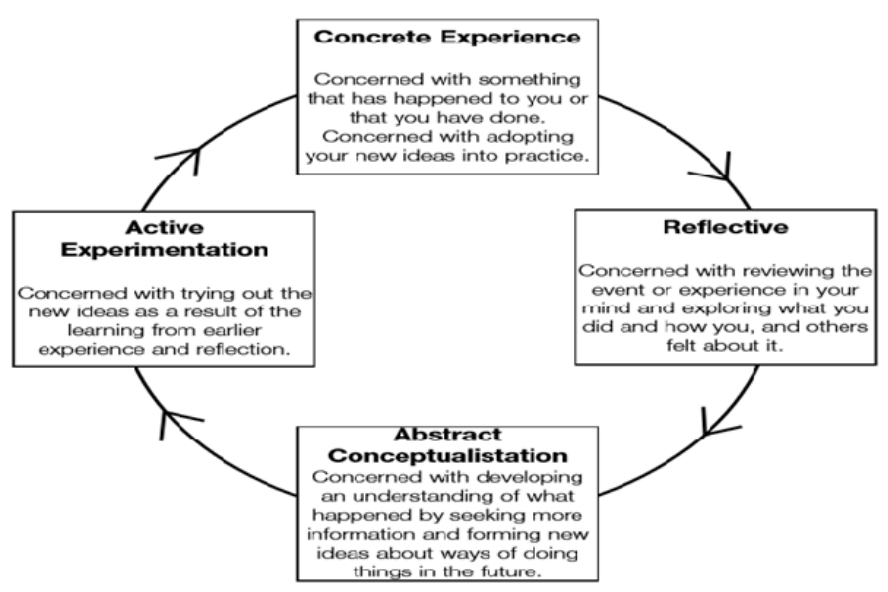

Figure 1. Kolb's experiential learning cycle (McClure, 2008, p. 4) 
Clark (2008) reports that Kolb's Learning Cycle consists of four different stages of learning from experience that can be penetrated at any stage. All four stages must be followed in sequence for successful learning to take place. The cycle also recommends that it is not only sufficient to have a concrete experience "DO" in order to learn, but also necessary to reflect on the experience "OBSERVE" to generalize and formulate concepts "THINK" that can be implemented to new situations. Hence, it makes it necessary for the learner to link between the theory and action by planning "PLAN", representing back to the theory. Built from Kolb's experiential learning cycle, Gibbs' Reflective Cycle (1988) (Figure 2) proposes that theory and practice enrich each other in a never-ending circle. This cycle has become adopted in professional education as a way to facilitate reflection.

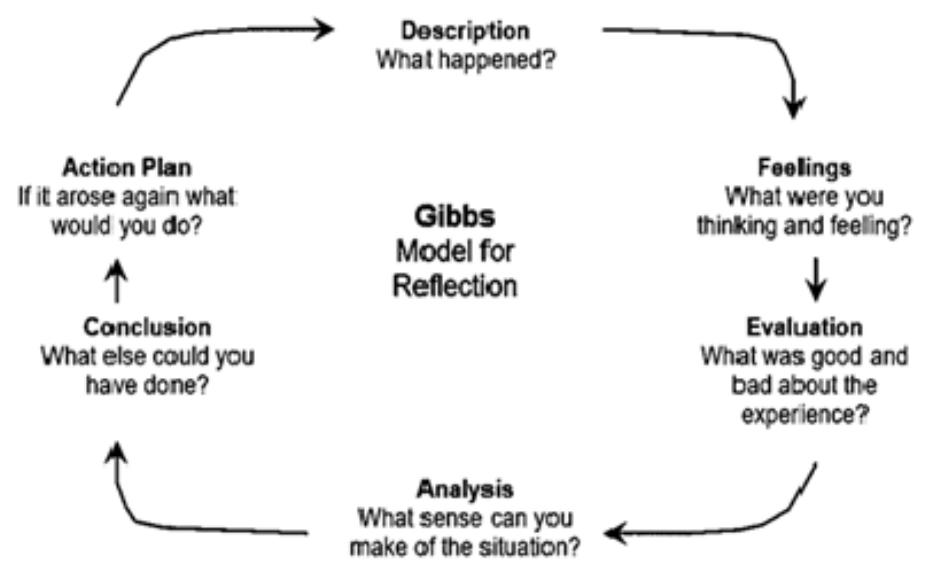

Figure 2. Gibbs' reflective cycle (Finlay, 2008, p. 8)

Gibbs' reflective cycle allows the reflective practitioners to analyze and evaluate the practice and make necessary improvements into their practice. It is comprised of six elements of reflection which shows a clear description of the situation, analysis of the "feelings", "evaluation" of the experience, "analysis" to make sense of the experience, "conclusion" and reflection upon experience to examine what you would do if the situation occurred again "action plan" (Essays UK, 2013). While models such as Gibbs' may offer useful basic questions to help structure reflection, some argue that a broader, more critically reflexive approach is needed. These arguments have encouraged more elaborate models to find favor in higher levels of professional practice and education. Jay \& Johnson (2002) developed a typology of reflection involving three intertwined dimensions: descriptive, comparative and critical reflection (Figure 3). In the descriptive dimension, the practitioner describes the matter for reflection. In the comparative dimension, the practitioner reframes the matter for reflection in the light of alternative views, perspectives and research. Then in the critical dimension, a new perspective is established given these various alternatives, their implications, and one's own morals and ethics. 


\begin{tabular}{|c|c|c|}
\hline Dimension & Definition & Typical questions \\
\hline Descriptive & Describe the matter for reflection & $\begin{array}{l}\text { What is happening? Is this working, and for whom? For whom } \\
\text { is it not working? How do I know? How am I feeling? What am } \\
\text { I pleased and/or concerned about? What do I not understand? } \\
\text { Does this relate to any of my stated goals, and to what extent } \\
\text { are they being met? }\end{array}$ \\
\hline Comparative & $\begin{array}{l}\text { Reframe the matter for reflection in light of } \\
\text { alternative views, others' perspectives, re- } \\
\text { search, etc. }\end{array}$ & $\begin{array}{l}\text { What are alternative views of what is happening? How do other } \\
\text { people who are directly or indirectly involved describe and } \\
\text { explain what's happening? What does the research contribute to } \\
\text { an understanding of this matter? How can I improve what's not } \\
\text { working? If there is a goal, what are some other ways of } \\
\text { accomplishing it? How do other people accomplish this goal? } \\
\text { For each perspective and alternative, who is served and who is } \\
\text { not? }\end{array}$ \\
\hline Critical & $\begin{array}{l}\text { Having considered the implications of the } \\
\text { matter, establish a renewed perspective }\end{array}$ & $\begin{array}{l}\text { What are the implications of the matter when viewed from these } \\
\text { alternative perspectives? Given these various alternatives, their } \\
\text { implications, and my own morals and ethics, which is best for } \\
\text { this particular matter? What is the deeper meaning of what is } \\
\text { happening, in terms of public democratic purposes of school- } \\
\text { ing? What does this matter reveal about the moral and political } \\
\text { dimension of schooling? How does this reflective process inform } \\
\text { and renew my perspective? }\end{array}$ \\
\hline
\end{tabular}

Figure 3. Typology of reflection: dimensions and guiding questions (Jay \& Johnson, 2002, p. 77)

Rolfe (2014) believes that the majority of models of reflection incorporate critical reflection on practice and experience, which would enable definition of learning requirements. Casey (2014) adds that these models have two main dimensions, i.e., iterative and vertical dimension. The first one reveals that the reflection process is triggered by experience, which later results in innovative understanding, and the intention and potential to operate discrepantly in reaction to future experience. On the other hand, vertical dimension incorporates discrepant level of reflection on experience.

In fact, different conceptions and models of reflective practice continue to emerge across different professional groups, and it seems neither possible nor desirable to fix on any one model as the definitive answer, hence different models are needed, at different levels, for different individuals, disciplines and organizations, to use in different contexts (Rolfe, 2014). Finlay (2008) adds that professional practice and education are likely to benefit from the stimulus and challenge provided by competing perspectives and multiple models, and also believes that "models need to be applied selectively, purposefully, flexibly and judiciously" (p. 10).

\subsection{Dimensions of Reflective Practice in Postgraduate Education}

Developing students' reflective thinking has been recognized as an essential goal for learning in higher education. It also aims at maintaining a flexible student-centered learning and teaching environment which represents three vital issues - innovation, engagement and globalization. What is more, it focuses on life-long learning skills that require using reflective thinking skills and adapting learning to new conditions with a flexible manner for making knowledge understandable (Almazrawi, 2014).

In the postgraduate educational experience, reflective practice plays a great role. Smith (2016) believes that the promotion of reflective practice in postgraduate education helps espousing active adult learning not only from a theoretical perspective, but also from the view of experience learning. Moreover, reflective practice provides postgraduate students with a possibility of achieving meanings from their experiences in order to contribute them to the incessant professional knowledge and practice evolvement. Hence, each postgraduate student evolves opinions grounded on previous experiences in order to generate new meaning from the new experience (Brooks \& Roberts, 2014).

According to Carl \& Strydom (2017), postgraduate education requires three major types of reflection: (i) 
technical reflection which is grounded on the scientific method of deductive and rational reasoning required for the knowledge generation; (ii) practical reflection that is necessary for the interpretation, description, and explanation of interactions; (iii) emancipatory reflection which is applied to the power of learning and the transformative actions, as the outcome of new knowledge generation.

Tsingos, Bosnic-Anticevich, \& Smith (2014) suggest four dimensions of reflective process and learning in postgraduate education, i.e., describe, analyze, transform meaning, and action. Brooks \& Roberts (2014) revised this taxonomy and incorporated knowledge and cognitive process dimensions. The knowledge dimension encompasses four categories, including factual, conceptual, procedural, and meta-cognitive knowledge. The first category, factual knowledge concerns the knowledge of discrete constituents of content, i.e., terminology, peculiar details, etc; while the conceptual knowledge is more complex, being organized as classifications, categories, principles of generalization, theories, models, and structure (Brooks \& Roberts, 2014). Procedural knowledge; and the third category stands for the knowledge of how to do something, concerning the usage of skills and algorithms, techniques and methods, which encompasses knowledge of "when to do what" (Smith, 2016). The last category, meta-cognitive knowledge stands for meta understanding, being both strategic and self-knowledge (Hung-Nam \& Leavell, 2011).

On the other hand, Garrett (2011) categorized the cognitive process dimension, referring to the learning process, into six groups. Firstly, it is necessary to retrieve appropriate information from the long-term memory. Secondly, it is necessary to construct meaning from all type of instructional messages, i.e., graphic, written, and oral. Thirdly, it is highly crucial to utilize procedures in given situations. Fourthly, analysis should be used to break material into elements and define how they are connected to each other and to the general purpose or structure. Fifthly, evaluation should be performed in order to make judgments on criteria, norms, and standards. Finally, creation stands for combining elements together in order to generate new structure or pattern.

AL-Tarawneh (2015) characterized five dimensions of reflective practice with each dimension requiring some essential skills as follows:

1) Thinking and observation through revealing the aspects of the problem and identifying the essential components.

2) Revealing the fallacies which are represented the ability to determine incorrect and irrational relations to achieve the target tasks in solving the problem.

3) Accessibility to conclusions through ability to access rational relations through visualizing the content of the problem and making logical conclusions.

4) Giving logical interpretations through giving logical meaning to the conclusions.

5) Setting suggested solutions that have been reflected on the ability to set logical steps to solve the problem, and then those steps form the expected mental visualizations for selected problems.

\subsection{Postgraduate Student as a Reflective Practitioner}

Within educational postgraduate programs, there is an increasing emphasis on the need for reflection as an integral part of learning to learn. The ability to reflect on one's learning and to learn from reflecting on experience is a fundamental skill necessary for learning and decision-making. It involves higher-level thinking skills and requires deep thinking and the ability to rationalize every decision made.

The term "reflective practitioner" repulses a mechanism of professional development. In this case, contextual comprehending and tacit knowledge play pivotal role in enabling the practitioner to reframe difficulties into solvable problems (Smith, 2016). The term also stands for a person's capability of reinvesting in learning though taking part in incessant education, looking for bigger challenges in his/her work, and by solving more complicated representations in terms of different recurring issues. The term "reflective practitioner" also involves performance awareness leading toward understanding the situations, so postgraduates can build knowledge and dimensional thinking skills that help them assess their thinking and cognitive base, and highly understanding complex issues which are reflected on their ability towards future problem solving (Swanwick et al., 2014). Hence, postgraduate students, being reflective practitioners, should understand how learning and reflection could be utilized in order to improve their professional practice (Brooks \& Roberts, 2014).

The notion of reflective practitioner in terms of postgraduate education can be summarized into four major perspectives; the first one regards acquiring learning as conduct, and this perspective appears to be expert/mentor centered; the second one concerns acquiring learning as understanding, which appears to be content concentrated; the third one stands for learning via knowledge construction, presupposing that postgraduate students construct 
meaning from acquired experiences, dialogues, and tacit knowledge, and; the last perspective regards learning as social practice, which turns learning into social activity (Brooks \& Roberts, 2014).

Nonetheless, Carl \& Strydom (2017) findings demonstrate that reflective learning is more complex and sophisticated in relation to postgraduate professional practitioners when compared with undergraduate learning. Hence, there is a requirement of re-conceptualizing the ways, in which students utilized reflective learning to evolve knowledge, understanding, and professional practice, via the iteration between deep and surface learning. They suggest utilizing and embedding e-portfolios in postgraduate education in order to scaffold and stimulate reflective practice. Such portfolios enable reflection, stimulate students to take ownership of their learning, to evolve as reflective practitioners and to open up professional dialogues between course participants (Garrett, 2011).

However, Al-Shokaa (2007) showed that high studies and bachelors students attained a good level of reflective thinking and also highlighted that there were some differences in reflective thinking attributed to the college type and in favor of the humanitarian colleges. In spite of the seemingly overwhelming evidence of the usefulness of reflective practice in higher education as illustrated above, there are inconclusive proofs for using reflective thinking among postgraduates in higher education programs.

\section{Methodology}

\subsection{Study Design}

This descriptive research aims to investigate the level of reflective practice amongst Saudi female postgraduate students at King Saud University. According to Burns \& Grove (2003, p. 201), descriptive research "is designed to provide a picture of a situation as it naturally happens". In order to collect data, quantitative approach was applied. Saudi female postgraduate students at KSU were requested to respond to a scale in order to identify their level of reflective practice and to find out the differences in students' levels of reflective practices between the literary and scientific sections. Creswell (2003) states, quantitative approach "employ strategies of inquiry such as experimental and surveys, and collect data on predetermined instruments that yield statistical data" (p. 18). Quantitative data was analyzed, described using descriptive statistical tools. The findings from quantitative research can be predictive, explanatory and confirming.

\subsection{Participants}

The intended population of this study was 1161 of postgraduate students, attending higher education programs in College of Education at King Saud University in the second semester of the year 2016-2017. A total number of 201 female postgraduate students were selected as the sample of this study by using random sampling techniques. Participants were enrolled in different bachelor and master programs such as: (Curriculum \& Instruction, Educational Administration, Education Technologies. etc). Their ages ranged from 30 to 45 years. Among the sample, $26.9 \%$ (54) of participants were students in scientific fields and $73.1 \%$ (147) were students in literary fields.

\subsection{Instruments}

An Arabic translated virgin of Reflective Practice Self-Assessment Scale (RSAS) (Wilkes \& Ashmore, 2014) was used to assess reflective practice of postgraduate students. RSAS contained two sections: demographic questions and three-point scale. The final version of Reflective Practice Self-Assessment Scale (RSAS) contained 30 items that covered five dimensions. The participants rated themselves on three-point scale (none/ some/ a lot). To acquire real results, face and content validity was judged by five experts and some items were revised according to their suggestions.

\subsection{Pilot Study}

The Arabic version of the scale was piloted to 20 students, who had similar characteristics of gender, age, level and study experience to those of the main study. The reliability analysis produced a Cronbach's Alfa of (0.74).

\subsection{Data Collection}

The data collection method is quantitative as it provides a numeric picture of the phenomenon and addresses the questions: how many and how much. Therefore, postgraduate students were requested to answer a scale that aimed at finding out how they assess their experiences in practicing reflective thinking. The responses were compared in order to determine whether there were any significant differences between the scientific and literary sections in relation to their reflective practice. 


\subsection{Data Analysis}

The analysis of the data was done by using SPSS V20. In the analysis, descriptive and analytical statistics were employed. According to Brief (2012) quantitative methods are characterized by the collection of information which can be analyzed numerically, the results of which are typically presented using statistics, tables and graphs. Among one of the best points in quantitative research is that numerical data facilitates comparisons between organizations or groups, as well as allowing determination of the extent of agreement or disagreement between respondents (Yauch \& Steudel, 2003, p. 473).

\section{Results}

\subsection{The Level of Reflective Practice amongst Saudi Female Postgraduate Students at KSU}

To answer the first question: "What is the level of reflective practice amongst Saudi female postgraduate students at King Saud University?", a descriptive statistical analysis has been used to identify the level of reflective practice amongst Saudi female postgraduate students at KSU. The results of this analysis reveal a decent level of reflective practice. The explored dimensions of this scale as the ability and freedom to reflect, questioning assumptions, considering others' viewpoints, using reflective methods/tools and frequency of the refection on events are all well addressed in terms of reflections. The results also show that the five dimensions of this scale demonstrate very close mean values. The highest mean value $(\mathrm{M}=2.77, \mathrm{SD}=.43)$ is for the questioning of assumptions. This indicates that the majority of the respondents tend to question assumptions more often in their reflective practice. The second rank is for the amount of reflection on events with a mean scoring $(\mathrm{M}=2.71, \mathrm{SD}=.88)$. The third rank is for their ability to take time and consider other points of view with a mean scoring $(\mathrm{M}=2.70, \mathrm{SD}=.49)$. The fourth rank is for their ability and freedom to reflect with a mean scoring $(\mathrm{M}=2.57, \mathrm{SD}=.53)$. The last rank is for their use of reflective methods and tools with a mean scoring $(\mathrm{M}=2.48, \mathrm{SD}=.54)$. Table1 below shows that the total mean value of each dimension of the scale.

Table 1. Descriptive statistics of the level of reflective practice amongst Saudi female postgraduate students at KSU

\begin{tabular}{lllll}
\hline No & Items & Mean & SD & Rank \\
\hline $\mathbf{1}$ & How much you reflect on events & 2.71 & 0.46 & 2 \\
$\mathbf{2}$ & Your use of reflection methods/tools & 2.48 & 0.54 & 5 \\
$\mathbf{3}$ & Considering other points of view & 2.70 & 0,49 & 3 \\
$\mathbf{4}$ & Your questioning of assumptions & 2.77 & 0.43 & 1 \\
$\mathbf{5}$ & Your ability/freedom to reflect & 2.57 & 0.53 & 4 \\
\hline
\end{tabular}

Considering the first dimension "How much you reflect on events", the majority of respondents indicate that they normally think and reason about events afterwards. This statement has the highest rank with a mean value of $(2.89, \mathrm{SD}=0.32)$, whereas the statement "I make decisions about events as they happen" has the lowest rank with a mean value of $(2.51, \mathrm{SD}=0.61)$. Table 2 below shows rank, mean and standard deviation values of each item in this dimension.

Table 2. Rank, mean and standard deviation values of the first dimension "How much do you reflect on events"

\begin{tabular}{lllll}
\hline No. & Items & Mean & SD & Rank \\
\hline $\mathbf{1}$ & I make decisions about events as they happen. & 2.51 & 0.61 & 6 \\
$\mathbf{2}$ & I change my behavior or actions as events happen. & 2.52 & 0.60 & 5 \\
$\mathbf{3}$ & I think about events and reasons for actions afterwards. & 2.89 & 0.32 & 1 \\
$\mathbf{4}$ & I talk to others about events/behavior afterwards. & 2.74 & 0.50 & 4 \\
$\mathbf{5}$ & I think proactively after events to plan future action. & 2.85 & 0.39 & 2 \\
$\mathbf{6}$ & I research/investigate issues to solve problems. & 2.77 & 0.47 & 3 \\
\hline & Total & $\mathbf{2 . 7 1}$ & $\mathbf{0 . 4 6}$ & - \\
\hline
\end{tabular}

When asked about their use of reflection methods and tools, the majority of respondents indicate that they only observe events and situations that involve them. This statement has the highest rank with a mean value of ( 2.88 , $\mathrm{SD}=0.33$ ), whereas the minority of respondents claim that they write notes to help them review and reflect on issues. This statement has the lowest rank with a mean value of $(1.63, \mathrm{SD}=0.70)$. Table 3 below shows rank, mean and standard deviation values of each item in this dimension. 
Table 3. Rank, mean and standard deviation values of the second dimension "Your use of reflection tools/methods",

\begin{tabular}{lllll}
\hline No. & Items & Mean & SD & Rank \\
\hline $\mathbf{1}$ & I write notes, which I review (e.g., diary, journal). & 1.63 & 0.70 & 6 \\
$\mathbf{2}$ & I talk with others about events / issues. & 2.82 & 0.40 & 2 \\
$\mathbf{3}$ & I explore theories, models, etc., relating to my issues. & 2.57 & 0.59 & 4 \\
$\mathbf{4}$ & I seek/get feedback from others about events/issues. & 2.71 & 0.48 & 3 \\
$\mathbf{5}$ & I make image/sound record of events/issues. & 2.29 & 0.71 & 5 \\
$\mathbf{6}$ & I observe events and situations that involve me. & 2.88 & 0.33 & 1 \\
\hline & Total & $\mathbf{2 . 4 8}$ & $\mathbf{0 . 5 4}$ & - \\
\hline
\end{tabular}

When asked about their other points of view concerning reflective practices, the majority of respondents claim that they understand their self-views in both subjective and objective manner. This statement has the highest rank with a mean value of $(2.90, \mathrm{SD}=0.31)$, whereas the minority of respondents claim that they seek standpoints of external concepts and theories. This statement has the lowest rank with a mean value of $(2.53, \mathrm{SD}=0.58)$. The implication of these results is that most respondents are of the opinion that understanding the self in both objective and subjective ways is an important consideration to successfully developing and achieving the reflective practices. Table 4 below shows rank, mean and standard deviation values of each item in this dimension.

Table 4. Rank, mean and standard deviation values of the third dimension "Considering other points of view"

\begin{tabular}{lllll}
\hline No. & Items & Mean & SD & Rank \\
\hline $\mathbf{1}$ & I understand my "self” views-subjective and objective. & 2.90 & 0.31 & 1 \\
$\mathbf{2}$ & I empathize with colleagues'/others' viewpoints. & 2.68 & 0.51 & 5 \\
$\mathbf{3}$ & I seek standpoints of external theories and concepts. & 2.53 & 0.58 & 6 \\
$\mathbf{4}$ & I look for relevant discussion (article, conference, etc.). & 2.69 & 0.54 & 4 \\
$\mathbf{5}$ & I look at research / evidence. & 2.72 & 0.53 & 2 \\
$\mathbf{6}$ & I try to make objective sense of social media. & 2.71 & 0.49 & 3 \\
\hline & Total & $\mathbf{2 . 7 0}$ & $\mathbf{0 . 4 9}$ & - \\
\hline
\end{tabular}

When asked about how they question assumptions, the majority of respondents claim that they question their own ideas. This statement has the highest rank with a mean value of $(2.88, \mathrm{SD}=0.36)$, whereas largest disparity was recorded against those claiming that they question books, newspapers and TV assumptions. This statement has the lowest rank with a mean value of $(2.41, \mathrm{SD}=0.57)$. This means that most of female postgraduate students at King Saud University question their ideas and beliefs more than they question assumptions in books, newspapers and TV. Table 5 below shows rank, mean and standard deviation values of each item in this dimension.

Table 5. Rank, mean and standard deviation values of the fourth dimension "Your questioning of assumptions?"

\begin{tabular}{lllll}
\hline No. & Items & Mean & SD & Rank \\
\hline $\mathbf{1}$ & I question my own ideas and beliefs. & 2.88 & 0.36 & 1 \\
$\mathbf{2}$ & Other people's points of view. & 2.81 & 0.41 & 3 \\
$\mathbf{3}$ & About task-related problems. & 2.86 & 0.34 & 2 \\
$\mathbf{4}$ & How and why I think the way I do (metacognition). & 2.67 & 0.50 & 5 \\
$\mathbf{5}$ & Books, newspapers, TV, etc. & 2.41 & 0.57 & 6 \\
$\mathbf{6}$ & Internet information. & 2.71 & 0.48 & 4 \\
\hline & Total & $\mathbf{2 . 7 2}$ & $\mathbf{0 . 4 3}$ & - \\
\hline
\end{tabular}

When asked to rank their freedom and ability to reflect, the majority of respondents claim that they are sufficiently empowered at both the individual level and the work place. This statement has the highest rank with a mean value of $(2.77, \mathrm{SD}=0.46)$, whereas the largest disparity was recorded against those who claim that they have necessary reflection knowledge, methods or tools. This statement has the lowest rank with a mean value of $(2.20, \mathrm{SD}=0.52)$. Table 6 below shows rank, mean and standard deviation values of each item in this dimension. 
Table 6. Rank, mean and standard deviation values of the fourth dimension "your freedom/ ability to reflect"

\begin{tabular}{lllll}
\hline No & Items & Mean & SD & Rank \\
\hline $\mathbf{1}$ & I have time or make time to reflect. & 2.42 & 0.62 & 5 \\
$\mathbf{2}$ & I have necessary reflection knowledge/ methods/ tools. & 2.20 & 0.52 & 6 \\
$\mathbf{3}$ & I overcome any self-imposed barriers, habits. & 2.65 & 0.53 & 2 \\
$\mathbf{4}$ & I understand how/why I think as I do (metacognition). & 2.49 & 0.57 & 4 \\
$\mathbf{5}$ & I am sufficiently empowered personally/at work. & 2.77 & 0.46 & 1 \\
$\mathbf{6}$ & I am free of negative influence by others. & 2.61 & 0.51 & 3 \\
\hline $\mathbf{m m}$ & Total & $\mathbf{2 . 5 7}$ & $\mathbf{0 . 5 3}$ & - \\
\hline
\end{tabular}

\subsection{Differences in the Level of Reflective Practice between the Literary and Scientific Fields}

To answer the second question: "Are there any significant differences in the level of reflective practice between the literary and scientific fields?" a comparison has been done between the literary and scientific fields in order to identify any significant differences between the two fields in the level of reflective practice. The results of this comparison show that there are statistically significant differences between the mean score of the literary fields and that of the scientific fields in favor of the latter. Data also shows that the two dimensions; "how much you reflect on events?" and "your questioning of assumptions" have no significant differences between the two fields, whereas the three other dimensions; "your use of reflection tools/methods?", "considering other points of view" and "your freedom/ ability to reflect" have significant differences in favor of the scientific fields. Tables 7 and 8 below show that reflective practices exist in the scientific fields more than they do in the literary fields.

Table 7. T-test for significant difference between means according to field of study

\begin{tabular}{llllll}
\hline & N & Mean Difference & SD & T & sig \\
\hline Literary & 147 & 78.1 & 8.1 & 2.59 & 0.011 \\
Scientific & 54 & 81.2 & 73.9 & & \\
\hline
\end{tabular}

Table 8. Results of the comparison between the literary and scientific fields in the level of reflective practice

\begin{tabular}{|c|c|c|c|c|c|c|}
\hline No. & Dimensions of Scale & Field of study & Mean & SD & T.Test & sig \\
\hline \multirow[t]{2}{*}{1} & How much you reflect on events & Literary & 16.1 & 1.16 & 1.83 & 0.07 \\
\hline & & Scientific & 16.6 & 1.20 & & \\
\hline \multirow[t]{2}{*}{2} & Your use of reflection methods/tools & Literary & 14.7 & 1.01 & 2.67 & 0.021 \\
\hline & & Scientific & 16.2 & 0.95 & & \\
\hline \multirow[t]{2}{*}{3} & Considering other points of view & Literary & 15.9 & 1.81 & -3.32 & 0.001 \\
\hline & & Scientific & 17.1 & 1.13 & & \\
\hline \multirow[t]{2}{*}{4} & Your questioning of assumptions & Literary & 16.3 & 1.91 & -1.49 & 0.13 \\
\hline & & Scientific & 16.67 & 1.23 & & \\
\hline \multirow[t]{2}{*}{5} & Your ability/freedom to reflect & Literary & 14.1 & 0.89 & 2.23 & 0.034 \\
\hline & & Scientific & 15.94 & 0.97 & & \\
\hline
\end{tabular}

\section{Discussion}

In exploring the level of reflective practice amongst Saudi female postgraduate students at KSU, it appears that most students have a decent level of reflective practices and skills. These results coincide with those of Al-Shokaa (2007) which show that high studies and bachelors students attain a good level of reflective thinking. According to Smith (2016), reflective practices can enable practitioners to develop a greater level of self-sameness concerning the impacts of their performances, and in the process to create opportunities for their professional growth and development. Therefore, having a high level of reflective practices and purposes will enable the postgraduate female students at KSU to develop more awareness concerning the impact of their various performances and practices and in the process to enhance their professional growth and development. This argument builds on what has been recommended by Casey (2014) that in order to achieve professional growth it is important for individuals to first understand their behaviors and develop a conscious awareness of their effects and actions.

Considering the first dimension "How much you reflect on events", this scale reveals significant amount of reflection within all sub-categories. At the same time, the highest peak of reflection occurs in thinking about events afterwards. Similarly, the lowest scores of reflection is reported in the statement "I make decisions about 
events as they happen". This evidence correlates with Casey's (2014) premise about the division in reflection. It implies that postgraduate students may experience difference in flexibility and adaptation to the ongoing changes in their social and learning environment. The rationale is that the reflection is needed to trigger a change; poor reflection or the absence of reflection is linked to limited flexibility of individuals. Smith (2016) emphasizes that learning, especially in a post-compulsory setting should be self-directed, which means that development of reflective skills should be an important academic and personal goal for contemporary students. Almazrawi (2014) also stresses that reflective practices need to be deployed in higher education courses to ensure high quality of students' learning outcomes. Thus, to be ready to meet the standards of higher educational establishments, students should work at advancing reflective skills, especially those that are connected to reflective on events.

The data received in the scale "Your use of Reflection Methods/Tools" indicates that postgraduate female students at KSU do not reveal advanced level of using reflection methods and tools. In particular, the worst results are linked to making written notes about daily events and experiences. In contrast, the highest level within this scale is represented by students' ability to observe events and situations that involve them. Linking the obtained evidence to the division of reflective skills proposed by Carl \& Strydom (2017) one may conclude that technical reflection is the most connected to deploying reflection tools and methods. In particular, thinking proactively after the occurrence of certain events implies using deduction to anticipate the issues and increase benevolent results in the future. In this regard, it is possible to assume that this type of reflection is somewhat greatly implemented by students.

Within the sub-scales of the dimension "Considering Other Points of View", the statement "I understand my self' views-subjective and objective" reveals the highest scores; whereas, smallest amount of reflection is depicted in the statement "I seek standpoints of external theories and concepts". This statistics means that postgraduate students are taught to self-reflect as well as identify and manage their bias rather well. Understanding of the grounds of personal views correlates with practical and emancipatory kinds of reflection as they are defined by Carl \& Strydom (2017). Both of these types are essential for learning and, thus, mastering these reflective skills is supposed to result in the improved academic performance. Moreover, the least developed skill implies that higher education should incorporate stronger demand for developing critical thinking in students. Questioning the source of information, the underlying causes of its revealing, and the credentials of sources that communicate this information, indicate that students should be engaged further to seek standpoint of the evidence that they perceive.

When asked about their "Questioning of Assumptions", the maximum is reported in the approach of questioning personal ideas and beliefs; meanwhile, the minimum is reported in questioning books, newspapers and TV assumptions. These results can be explained by the fact that within higher education level, students are actively encouraged to be skillful, independent, and creative in finding solutions of self-related issues. That is why they are used to deploy reflective techniques quite often. Hence, the minimal level in this scale points to the insufficient critical thinking while assessing the others' views. Therefore, it is natural to deduce that this learning objective, as suggested by Carl \& Strydom (2017), needs to receive special attention in postgraduate education.

Within the sub-scales of the last dimension "Ability, Freedom to Reflect", the maximum scores are assigned to the statement about decent level of empowerment at work and at an individual level, whereas the minimum scores are recorded against those who claim that they have necessary reflection knowledge, methods or tools. The recognition of this issue builds on what has been detected by Al-Shokaa (2007) that in spite of the seemingly overwhelming evidence of the usefulness of reflective practice in higher education, there are inconclusive proofs for using reflective thinking among postgraduates in higher education programs. Besides, one should stress that the ability and freedom to reflect requires joining three-partite approaches towards reflection technical, practical, and emancipatory (Carl \& Strydom, 2017). This complex approach is assumed to be linked to the lowest scores of the present dimension.

However, the overall decent level of reflective practices detected in this research is a testament that postgraduate female students at King Saud University have the capabilities to grasp the different reflective practices and skills. These results indicate that reflection is an essential learning objective that must be incorporated in higher educational establishments and modern courses within both scientific and literary fields. According to El-Gilany \& Abusaad (2013), reflective education practitioners are active, persistent, careful, skeptical, rational, and proactive. These practices are specifically important for teachers who can employ them as they impart knowledge on their students. Almorshid (2014) also adds that unless teachers can develop critical reflection practices, students will stay trapped and consumed in unexamined judgments, expectations, assumptions, and interpretations. This point was clearly critical when the students were asked about their abilities to question assumptions since this can enable them to develop critical judgment skills (El-Gilany \& Abusaad, 2013). 
More interesting are the results of the study in terms of the differences between the literary and scientific fields in their level of reflective practice. Findings in this respect display that there are some reflective requirements and skills which are more common in the scientific fields than they are in the literary fields. These findings imply that various types and dementias of reflective practice, as characterized by AL-Tarawneh (2015) and Carl \& Strydom (2017), are well incorporated in postgraduate scientific education. It also means that students from scientific fields might be more influenced by learning experiences, teaching methods, and scientific content more than other postgraduate students. This insight evokes an assumption that within the scientific educational establishments students are well-engaged to master and deploy their technical and practical reflective skills. This premise can be a relevant topic for conducting further studies in the field of students' reflections in an academic realm.

Summarizing the discussion section, it is appropriate to accentuate that Saudi female postgraduate students at KSU reveal a decent level of reflective skills. The explored sub-scales as; the ability and freedom to reflect, questioning assumptions, considering others' viewpoints, using reflective methods/tools, and frequency of the refection on events are all well-addressed in terms of reflections. The ability to reflect is considered an essential learning objective; therefore, higher educational establishments should incorporate it actively in the modern courses within both scientific and literature settings. In terms of the differences between science and literature students, the former group depicts somewhat better reflective skills in all sub-scales except the first one (the amount of reflection on events) and the fourth one (the questioning of assumptions).

\section{Conclusion}

The main purpose of this study is to investigate the level of reflective practice of Saudi female postgraduate students who are attending higher education programs in College of Education at King Saud University. Descriptive method was used to answer study questions. This study observed that most of students demonstrate moderate level of reflective practice. It was deemed that most participants tend to question their own ideas more often in their reflective practice and they normally think and reason about events afterwards. Moreover, this study indicated that reflective practice should be considered as a requirement in the context of the higher education programs. Therefore, postgraduate students will be more motivated to use it. As the postgraduate students should think reflectively to face the problem in their real life and relate theory and practice. Actually, it can be concluded that reflective thinking can help the students to be successful in learning and in their real life. Additionally, the extent to which the instructor can participate in such reflective activities ought to be examined.

What is more, results showed the lack of capacity and freedom to reflect and to use reflective methods and tools among female postgraduate students at KSU. Students are expected not only to reflect as a part of their subject-based studies, but also to reflect on their learning and development of skills. There is an increasing emphasis on the need for reflection within higher education as an integral part of learning to learn. Reflective thinking and its teaching method is a required mode of thinking that should be used along with other modes of thinking like metacognition, critical thinking, analytical thinking, and creative thinking among modern education approaches during higher education process.

As a consequence of this study, the results showed that scientific students are better in using reflection methods and tools than literary students. The mean score of scientific students are higher in understanding their subjective and objective views. Moreover, scientific students got the highest scores in their freedom and ability to reflect. It may be remarked that scientific students are very high in reflective thinking in comparison to literary students. It means that students from scientific fields might be more influenced by learning experiences, teaching methods, and scientific contents more than other postgraduate students. However, there was no statistically significant difference between scientific and literary students in the way they question assumptions. Finding related with the amount of reflection on events showed that there was no significant difference. Further studies are needed to investigate the factors that facilitate or hinder the experience of using reflective thinking in both literary and scientific fields.

Finally, the present findings tend to be meaningful data that is significant in determining whether students entail good reflective experiences or not during their learning process at KSU. Such experience is beneficial in shaping their future society and dealing with different changes in social, cultural, political, economic, technological scopes. Every student need to think reflectively in their learning which may help them to face the challenges of 21 st century.

\section{Recommendations}

Based on the results of the present study, the following recommendations are offered for Saudi postgraduate instructors and program developers in particular and for researchers in education in general: 
1) For Saudi postgraduate instructors, it is clearly indicated from the analysis of data that postgraduate students need to be involved in an environment that encourages reflective thinking. It is strongly suggested that postgraduate instructors should do more to utilize reflective thinking and its teaching methods along with other modes of thinking like metacognition, critical thinking, analytical thinking, and creative thinking among modern education approaches during higher education process. Instructors should also change their teaching habits offering their students new and innovative opportunities to improve their reflective practice, to monitor their own learning and to practice their thinking skills in and outside the classroom.

2) For Saudi postgraduate program developers, it may be advantageous to evaluate and update postgraduate program courses in order to meet the needs of new-generation students, giving particular attention to tasks and requirements that support reflective teaching and learning and help students to extend their thinking skills outside the classroom.

3) For educational researchers, there is a need for future replications of this study in order to support the validity of the findings. Further analysis of the educational level, gender and age dimensions and their relation to the level of reflective practice is also needed. Possible areas for further research can address students' achievement and motivation in relation to the their level of reflective practice, instructors' perceptions and preparedness to utilize reflective thinking in their instruction and possible ways to make it suit the unique needs and requirements of students. It is also recommended to explore the challenges of using reflection providing practical suggestions to eliminate them and addressing at the same time the gap found in its literature.

\section{References}

Al-Ahdal, A. (2014). Reflective Teaching and Language Teacher Education Programs: A Milestone in Yemen and Saudi Arabia. Journal of Language Teaching and Research, 5(4), 759-768. https://doi.org/10.4304/jltr.5.4.759-768

Almazrawi, G. (2014). Exploring the Reflective Practice among Saudi Female In-Service Teachers (Doctoral dissertation, Boise State University).

Almorshid, Y. (2014). Levels of Reflective Thinking among Al-Jouf University Students: Cross-sectional Study. Taiba Journal for Educational Sciences, 9(2), 184-163. Retrieved from https://goo.gl/Vn7N3I

Al-shokaa, A. (2007). Reflective thinking level among high studies and bachelors students in An- Najah National University. An- Najah University journal for research-Natural sciences, 2(4). Retrieved from https://goo.gl/6ZCLr8

Al-Tarawenh, A. (2015). Reflective Thinking and its Relationship with Future Problem Solving for Mutah University Students. British Journal of Humanities and Social Sciences, 13(2).

Bolton, G. (2014). Reflective practice: Writing and professional development (4th ed.). London: Kogan Page.

Brief, A. I. (2012). Qualitative and Quantitative Research Techniques for Humanitarian Needs Assessment.

Brooks, S., \& Roberts, E. (2014). "Simultaneous immersion": How online postgraduate study contributes to the development of reflective practice among public service practitioners. Interactive Learning Environments, 24(7), 1692-1705. http://dx.doi.org/10.1080/10494820.2015.1041406

Burns, N., \& Grove, S. K. (2003). Understanding Nursing Research, Saunders, Pennsylvania.

Buwert, P. (2012). The Reflective Practitioner by Donald Schon. Retrieved from https://goo.gl/c6GFCR

Cano, F. (2005). Epistemological beliefs, approaches to learning, and academic performance. British Journal of Educational Psychology, 75, 1-21. http://dx.doi.org/10.1348/000709904X22683

Carl, A., \& Strydom, S. (2017). E-portfolio as reflection tool during teaching practice: The interplay between contextual and dispositional variables. South African Journal of Education, 37(1), 1-10. https://doi.org/10.15700/saje.v37n1a1250

Casey, T. (2014). Reflective practice in legal education: The stages of reflection. Clinical Law Review, 20, 317-354.

Creswell, J. (2003). Research design: Qualitative, quantitative and mixed methods approaches (2nd ed.). Thousand Oaks, CA: SAGE Publications.

Deville, P. (2010). Mentoring reflective practice in pre-service teachers. EABR \&ETLC Conference Proceeding: The voice of Australian Science Teachers reconstructing the mentoring provided by preservice Lecturers, especially in the development of professional reflective practice. 
Ekebergh, M. (2007). Lifeworld-based reflection and learning: a contribution to the reflective practice in nursing and nursing education. Reflective Practice, 8(3), 331-343. https://doi.org/10.1080/14623940701424835

El-Gilany, A. H., \& Abusaad, F. E. S. (2013). Self-directed learning readiness and learning styles among Saudi undergraduate nursing students. Nurse Education Today, 33(9), 1040-1044. http://dx.doi.org/10.1016/j.nedt.2012.05.003

Essays, UK. (2013). Models of Reflective Practice. Retrieved from https://goo.gl/aKMohu

Fielden, K. (2008). Evaluating Critical Reflection for Postgraduate Students in Computing. Issues in Informing Science and Information Technology. ISI Journal, 2. Retrieved from https://goo.gl/qDNK5G

Finlay, L. (2008). Reflecting on Reflective practice. Practice-based Professional Learning Journal, 52, 1-27. A discussion paper prepared for PBPL CETL. Retrieved from https://goo.gl/g53fTc

Garrett, N. (2011). An e-portfolio design supporting ownership, social learning, and ease of use. Journal of Educational Technology \& Society, 14(1), 187-202.

Hung-Nam, K., \& Leavell, A. (2011). Reading strategy instruction, metacognitive awareness, and self-perception of striving college developmental readers. Journal of College Literacy and Learning, 37, 399-415.

Jay, J. K., \& Johnson, K. L. (2002). Capturing complexity: a typology of reflective practice for teacher education. Teaching and Teacher Education, 18, 73-85. https://doi.org/10.1016/S0742-051X(01)00051-8

Khalid, F., Ahmad, M., Karim, A. A., Daud, M. Y., \& Din, R. (2015). Reflective Thinking: An Analysis of Students' Reflections in Their Learning about Computers in Education. Creative Education, 6, 2160-2168. http://dx.doi.org/10.4236/ce.2015.620220

Larrivee, B. (2008). Development of a tool to assess teachers' level of reflective practice. Reflective Practice, 9(3), 341-360. http://dx.doi.org/10.1080/14623940802207451

Lee, I. (2007). Preparing pre-service English teachers for reflective practice. ELT Journal, 61(4), 321-329. https://oi.org/10.1093/elt/ccm022

Lucas, U., \& Leng Tan, P. (2006). Assessing levels of reflective thinking: the evaluation of an instrument for use within accounting and business education. Paper presented to the first Pedagogic Research in Higher Education Conference, Liverpool Hope University; Liverpool.

McClure, P. (2008). Reflection on Practice. School of Health Sciences, University of Ulster. Retrieved from https://goo.gl/IDCTwe

Nwizu, S. (2011). Implementing internal quality assurance strategies. International Journal of Education Research, 11(1), 150-160.

Phan, H. P. (2007). Examination of student learning approaches, reflective thinking, and self-efficacy beliefs at the University of the South Pacific: A path analysis. Educational Psychology, 27(6), 789-806. https://doi.org/10.1080/01443410701349809

Rolfe, G. (2011). Critical Reflection in Practice. London: Palgrave Macmillan.

Rolfe, G. (2014). Rethinking reflective education: What would Dewey have done? Nurse Education Today, 34(8), 1179-1183. http://dx.doi.org/10.1016/j.nedt.2014.03.006.

Sibahi, R. (2015). Exploring Reflective Practice among College EFL Teachers in Saudi Arabia. University of Exeter United Kingdom. Arab World English Journal (AWEJ), 6(2), 337-351. Retrieved from https://goo.gl/VY9Dbd

Smith, K. (2016). Reflection and person-centeredness in practice development. International Practice Development Journal, 6(1), 1-12. https://doi.org/10.19043/ipdj.61.012

Smith, M., \& Trede, F. (2013). Reflective practice in the transition phase from university student to novice graduate: Implications for teaching reflective practice. Higher Education Research \& Development, 32(4), 632-645. http://dx.doi.org/10.1080/07294360.2012.709226

Swanwick, R., Kitchen, R., Jarvis, J, McCracken, W, O’Neil, R., \& Powers, S. (2014). Following Alice: theories of critical thinking and reflective practice in action at postgraduate level. Teaching in Higher Education, 19(2), 156-169. http://dx.doi.org/10.1080/13562517.2013.836099

Tarrant, P. (2013). Reflective practice and professional development. London: SAGE Publications. https://doi.org/10.4135/9781526402318 
Taşkin Can, B., \& Yildirim, C. (2014). The instrument for determining the levels of reflective thinking among elementary school students. Educational Research and Reviews, 9(1), 9-16. https://doi.org/10.5897/ERR12.093

Thorpe, K. (2004). Reflective Learning Journals: From Concept to Practice. Reflective Practice, 5, 328-343. http://dx.doi.org/10.1080/1462394042000270655

Tsingos, C., Bosnic-Anticevich, S., \& Smith, L. (2014). Reflective practice and its implications for pharmacy education. American Journal of Pharmaceutical Education, 78(1), 1-10. https://doi.org/10.5688/ajpe78118

Yauch, C. A., \& Steudel, H. J. (2003). Complementary Use of Qualitative and Quantitative Cultural Assessment Methods. Organizational Research Methods, 6(4), 465-48. https://doi.org/10.1177/1094428103257362

YuekMinga, H., \& Abd Manaf, L. (2014). Assessing learning outcomes through students' reflective thinking. Social and Behavioral Sciences, 152, 973-977. Retrieved from https://doi.org/10.1016/j.sbspro.2014.09.352

\section{Copyrights}

Copyright for this article is retained by the author, with first publication rights granted to the journal.

This is an open-access article distributed under the terms and conditions of the Creative Commons Attribution license (http://creativecommons.org/licenses/by/4.0/). 